\title{
A ASSISTÊNCIA DE ENFERMAGEM E O CUIDADO FAMILIAR ÀS CRIANÇAS COM NECESSIDADES ESPECIAIS DE SAÚDE: UMA REVISÃO INTEGRATIVA
}

\author{
NURSING CARE AND FAMILY CARE FOR CHILDREN WITH SPECIAL HEALTH NEEDS: INTEGRATIVE \\ LITERATURE REVIEW
}

\author{
Ana Luiza Rodrigues Inácio ${ }^{a}$, Ana Paula Gomes Lima Peixoto ${ }^{b}$ \\ aanaluizarodriguesinacio@yahoo.com.br, bpaulapeixoto06@gmail.com \\ Universidade Federal de Uberlândia - Uberlândia (MG), Brasil
}

Data de recebimento do artigo: 10/03/2017

Data de aceite do artigo: 26/07/2017

\section{RESUMO}

Introduçáo: Crianças com necessidades especiais de saúde precisam continuamente de serviços que ofereçam assistência para além dos requeridos por crianças em geral. Objetivo: Descrever a assistência de enfermagem e o cuidado familiar prestados às crianças com necessidades especiais de saúde. Materiais e métodos: Revisão integrativa na base de dados da Biblioteca Virtual em Saúde (BVS-Bireme), com os descritores "crianças com deficiência", "cuidados de enfermagem" e "cuidadores". Apenas artigos sobre o tema foram incluídos, publicados em língua portuguesa, no período de janeiro/2000 a dezembro/2015, disponíveis on-line, na íntegra e gratuitamente. Resultados: Ainda existe um grande despreparo familiar em dar continuidade ao tratamento domiciliar da criança com necessidades especiais. Como justificativa, aponta-se um distanciamento entre a equipe de saúde e a família do paciente, cenário no qual o núcleo familiar não tem sido atendido como um todo, uma vez que a equipe acaba centrando sua atenção somente aos cuidados biomédicos. Ressalta-se ainda que há uma série de cuidados especiais, o que exige mais preparação e capacitação por parte da enfermagem para atuação nas demandas de assistência à criança e à família. Conclusóes: Ao abordar a assistência profissional de saúde e o contexto familiar, com suas diversas faces do cuidar, reconhece-se a necessidade da busca pelo crescimento teórico e pela capacitação na área, como concepçôes abrangentes para lidar com a criança com necessidades especiais de saúde que respeitem sua complexidade e subjetividade para um cuidado de qualidade.

Palavras-chave: Crianças com deficiência; cuidados de enfermagem; cuidadores.

\section{ABSTRACT}

Introduction: Children with special health care needs continuously demand services that provide support beyond those required by children in general. Objectives: Describing the nursing and family care provided to children with special health needs. Materials and method: Integrative literature revision in the Virtual Health Library database (BVS-Bireme), considering the descriptors "children with disabilities", "nursing care" and "caregivers". Only articles about the selected theme were included, which were published in Portuguese, during the period from January 2000 to December 2015, available online, in full and free. Results: There is still a great lack of preparation of the families to continue the treatment of children with special needs at home. As a justification, we can point a distance between the health staff and the patient's family, a scenario in which the family nucleus has not been assisted as a whole, since the staff focuses its attention only on biomedical care. Furthermore, there is so many special cares, which requires more preparation and qualification for the nursing related to the demands for care of the child and its family. Conclusion: When studying the professional health care and the family context, with their various aspects of care, it is recognized the need to seek theoretical growth and training in the area, such as the comprehensive concepts to deal with the child with special needs that respect its complexity and subjectivity for a high-quality care.

Keywords: Children with disabilities; nursing care; caregivers. 


\section{Introdução}

No Brasil, as crianças com necessidades especiais de saúde são denominadas Crianes ${ }^{1}$; na literatura internacional Maternal and Child Health Bureau, são denominadas como Children with Special Health Care Needs $(\mathrm{CSHCN})^{2}$. As Crianes apresentam condiçóes especiais de saúde com demanda de cuidados contínuos, sejam eles de natureza temporária ou permanente, e necessitam de serviços médicos e sociais para além dos requeridos por outras crianças ${ }^{3}$.

Essas crianças podem apresentar várias demandas de cuidados, aos quais foram classificados segundo sua tipologia em cinco grupos: de desenvolvimento, que são os atrasos no desenvolvimento neuropsicomotor; de tecnologias, como o uso de sondas e cateteres implantados; de medicamentos, como o uso de anticonvulsivantes ou antirretrovirais; de cuidados habituais modificados, que são os cuidados especiais com alimentaçáo e higiene; de cuidados mistos, que incluem várias demandas conjuntas ${ }^{4}$.

A Organização das Nações Unidas (ONU) estima que, em todo o mundo, há pelo menos 150 milhóes de crianças com algum tipo de deficiência, representada por qualquer perda ou anormalidade estrutural, funcional ou psíquica, física ou anatômica ${ }^{5}$. A necessidade especial de cuidados de saúde não está apenas relacionada à condição individual e intrínseca da criança, mas também ao ambiente social ${ }^{6}$. Portanto, cuidar de

Uma Criane exige preparo e conhecimento dos profissionais de saúde, assim como atençáo de seus familiares para que o cuidado a domicílio seja adequado ${ }^{7}$.

$\mathrm{O}$ interesse pelo assunto proposto na área de enfermagem emergiu do contato de uma das pesquisadoras (como acadêmica) com crianças com diferentes deficiências, proporcionado por um estágio extracurricular não obrigatório em uma escola de educação básica. A experiência ocorreu em salas de aulas comuns, com a presença de uma média de vinte alunos, sendo dois alunos com necessidades especiais por sala. Dessa forma, o fato de essas crianças possuírem um atendimento educacional especializado na escola, visando à inclusão social, levantou questionamentos relacionados à possibilidade destas também precisarem de um atendimento especializado na área da saúde. Acreditamos que a atuação da enfermagem nesse campo representa um desafio. Devido aos avanços tecnológicos e socioculturais, mais crianças sobrevivem, e muitas delas podem apresentar sequelas relacionadas a diferentes tipos de enfermidades que resultam em necessidades especiais.

A partir dessas consideraçóes, temos como hipótese a existência de uma demanda de cuidados diferenciados e especializados para essas crianças, os quais vão exigir uma melhor qualificação da enfermagem e daqueles que estão diretamente envolvidos no cenário apresentado, como os familiares. Nesse contexto, este estudo teve como objetivo descrever a assistência de enfermagem e o cuidado familiar prestados às Crianes.

\section{Metodologia}

Para o desenvolvimento deste estudo, utilizou-se como metodologia a revisão integrativa da literatura, baseada no referencial de Mendes, Silveira e Galvão ${ }^{8}$, por meio de análise construída a partir de seis etapas, com a finalidade de obter melhor entendimento sobre a temática com base em estudos anteriores. As etapas são: identificação do tema e seleção da hipótese ou questão de pesquisa para a elaboraçáo da revisão integrativa; estabelecimento de critérios para inclusão e exclusão de estudos/amostragem ou busca na literatura; definição das informaçóes a serem extraídas dos estudos selecionados/categorização dos estudos; avaliação dos estudos incluídos na revisão integrativa; interpretação dos resultados; apresentação da revisão/síntese do conhecimento.

Inicialmente, realizou-se uma busca avançada na base de dados informatizada da Biblioteca Virtual em Saúde (BVS-BIREME). Para a busca, foram utilizados os seguintes descritores de assuntos nos campos de pesquisa da base de dados: (A) "crianças com deficiência"; (B) "cuidados de enfermagem"; (C) "cuidadores" (C). Foram incluídos apenas os artigos sobre o tema que foram publicados em língua portuguesa durante o período de janeiro de 2000 a dezembro de 2015, que estavam disponibilizados on-line, na íntegra e gratuitamente. No caso, foram excluídos: teses, dissertaçóes e outros; artigos que não foram publicados em língua portuguesa; que não estão dentro do período proposto, de janeiro de 2000 a dezembro de 2015; sem disponibilidade on-line, na íntegra e gratuitamente.

Para a avaliação dos estudos selecionados, realizou-se leitura de todos os artigos na íntegra em busca de informaçóes sobre o tema proposto e posterior organizaçáo, por meio da construçáo de um quadro visando favorecer as discussóes e análises segundo os seus conteúdos descritivos.

Quando realizada a combinação entre palavras-chaves, no cruzamento A (crianças com deficiência) + B (cuidados de Enfermagem), foram encontrados 837 trabalhos, sendo que 632 destes foram eliminados por não estarem disponíveis na íntegra, 157 por publicação em língua estrangeira, 27 por limitação de ano de publicação, 5 por estarem duplicados, 3 por serem teses, totalizando 13 artigos. No cruzamento A (crianças com deficiência) + C (cuidadores), foram encontrados 588 trabalhos, sendo que 301 trabalhos foram eliminados por não estarem disponíveis na íntegra, 227 por publicação em língua estrangeira, 31 por limitação de ano de publicação, 6 por estarem duplicados, 5 por serem teses, totalizando 18 artigos. No 
cruzamento B (cuidados de enfermagem) + C (cuidadores), foram encontrados 6175 trabalhos, sendo que 3218 trabalhos foram eliminados por não estarem disponíveis na íntegra, 2441 por publicação em língua estrangeira, 42 por limitaçáo de ano de publicaçáo, 68 por estarem duplicados, 58 por serem teses, totalizando 348 artigos. Por fim, no cruzamento A (crianças com deficiência) + B (cuidados de enfermagem) + C (cuidadores) foram encontrados 97 trabalhos, 38 destes foram eliminados por não estarem disponíveis na íntegra, 40 por publicação em língua estrangeira, 8 por limitação de ano de publicação, 2 por estarem duplicados, 3 por serem teses, totalizando 6 artigos. Sendo assim, este estudo foi constituído por onze artigos, os quais atenderam à temática proposta e aos critérios de inclusão e exclusão previamente estabelecidos. Não foram incluídos trabalhos cuja temática constituía crianças que faziam parte dos grupos de demanda de cuidados medicamentosos e demandas tecnológicas. A apresentaçáo dos dados e discussão dos resultados realizou-se de forma descritiva e comparativa, apoiando-se na literatura científica do assunto e visando atender ao objetivo proposto no estudo.

\section{Resultados e discussões}

Para maior clareza e facilidade de leitura, apresentamos o Quadro 1, com algumas informaçóes sobre os artigos analisados.

Quadro 1: Distribuição dos artigos selecionados e suas respectivas especificações.

\begin{tabular}{|c|c|c|c|c|c|}
\hline & $\begin{array}{l}\text { Local da } \\
\text { pesquisa }\end{array}$ & $\begin{array}{l}\text { Período da } \\
\text { pesquisa }\end{array}$ & $\begin{array}{l}\text { Método de } \\
\text { pesquisa }\end{array}$ & Objetivo principal & Principais resultados \\
\hline $\begin{array}{l}\text { Crianes: impacto no } \\
\text { cotidiano familiar }\end{array}$ & & $\begin{array}{l}\text { Entre } 2003 \\
\text { e } 2013\end{array}$ & $\begin{array}{l}\text { Revisão } \\
\text { integrativa }\end{array}$ & $\begin{array}{l}\text { Descrever por meio } \\
\text { da literatura científi- } \\
\text { ca o impacto que as } \\
\text { demandas de cuidados } \\
\text { das Crianes causam em } \\
\text { suas famílias }\end{array}$ & $\begin{array}{l}\text { A temática tem sido investigada } \\
\text { prioritariamente em estudos inter- } \\
\text { nacionais, e o impacto ocorre na } \\
\text { transmissão do diagnóstico e acarreta } \\
\text { repercussôes financeiras, na saúde e } \\
\text { no cotidiano social dos membros da } \\
\text { família }\end{array}$ \\
\hline $\begin{array}{l}\text { Rotinas de cuidados das } \\
\text { famílias de crianças com } \\
\text { paralisia cerebral (PC) }\end{array}$ & Santa Catarina & $\begin{array}{l}\text { Junho a } \\
\text { julho de } \\
2013\end{array}$ & $\begin{array}{l}\text { Estudo } \\
\text { descritivo, com } \\
\text { abordagem } \\
\text { qualitativa }\end{array}$ & $\begin{array}{l}\text { Conhecer as rotinas de } \\
\text { cuidado das famílias de } \\
\text { crianças com PC }\end{array}$ & $\begin{array}{l}\text { Emergiram duas categorias: rotinas } \\
\text { de cuidado das famílias com criança } \\
\text { e rotinas de cuidado com as terapias } \\
\text { e a frequência escolar }\end{array}$ \\
\hline $\begin{array}{l}\text { Cuidado centrado na } \\
\text { família no contexto da } \\
\text { criança com deficiência } \\
\text { e sua família: uma } \\
\text { análise reflexiva }\end{array}$ & $\begin{array}{l}\text { Florianópolis, } \\
\text { Santa Catarina }\end{array}$ & - & $\begin{array}{l}\text { Reflexão } \\
\text { teórico-filosófica }\end{array}$ & $\begin{array}{l}\text { Refletir sobre a prática } \\
\text { da equipe de saúde no } \\
\text { cuidado à família da } \\
\text { criança deficiente, à luz } \\
\text { dos pressupostos do } \\
\text { cuidado centrado na } \\
\text { família (CCF) }\end{array}$ & $\begin{array}{l}\text { É possível perceber que ainda existe } \\
\text { um distanciamento entre a equipe } \\
\text { de saúde e a família, pois a família } \\
\text { da criança com deficiência ainda } \\
\text { não é atendida como unidade pelos } \\
\text { profissionais que centram o cuidado } \\
\text { no paradigma biomédico }\end{array}$ \\
\hline $\begin{array}{l}\text { Acessibilidade de } \\
\text { crianças com deficiência } \\
\text { aos serviços de saúde na } \\
\text { atençáo primária }\end{array}$ & Goiânia, Goiás & $\begin{array}{l}\text { Março a } \\
\text { junho de } \\
2011\end{array}$ & $\begin{array}{l}\text { Estudo } \\
\text { qualitativo }\end{array}$ & $\begin{array}{l}\text { Compreender como } \\
\text { ocorre a acessibilida- } \\
\text { de das crianças com } \\
\text { deficiência à atenção } \\
\text { primária em saúde } \\
\text { a partir da visão dos } \\
\text { profissionais da estraté- } \\
\text { gia de saúde da família }\end{array}$ & $\begin{array}{l}\text { Observaram-se algumas iniciativas } \\
\text { que facilitaram a acessibilidade, como } \\
\text { visitas domiciliares e priorizaçáo do } \\
\text { atendimento. Assim, pode-se com- } \\
\text { preender que os fatores dificultadores } \\
\text { do acesso das CcD aos serviços afeta } \\
\text { negativamente a qualidade da assistên- } \\
\text { cia e prejudica o desenvolvimento das } \\
\text { potencialidades dessas crianças }\end{array}$ \\
\hline $\begin{array}{l}\text { A influência do toque } \\
\text { no cuidado às crianças } \\
\text { especiais }\end{array}$ & $\begin{array}{l}\text { Porto Alegre, } \\
\text { Rio Grande do } \\
\text { Sul. }\end{array}$ & $\begin{array}{l}\text { Julho a } \\
\text { agosto de } \\
2011\end{array}$ & $\begin{array}{l}\text { Pesquisa } \\
\text { qualitativa }\end{array}$ & $\begin{array}{l}\text { Identificar a influência } \\
\text { do toque no cuidado às } \\
\text { Crianes na percepçáo } \\
\text { dos trabalhadores }\end{array}$ & $\begin{array}{l}\text { O toque é ferramenta que influencia } \\
\text { no bem-estar das crianças e } \\
\text { caracteriza-se por ser instrumento } \\
\text { de comunicação alternativa e modo } \\
\text { de aproximaçáo entre o profissional } \\
\text { e a criança, possibilitando a } \\
\text { criaçáo de um vínculo positivo e, } \\
\text { consequentemente, favorecendo o } \\
\text { processo de reabilitação }\end{array}$ \\
\hline
\end{tabular}




$\begin{array}{lllll}\begin{array}{l}\text { Facilidades e dificulda- } \\ \text { des da família no cuida- }\end{array} & \text { João Pessoa, } \\ \text { do à criança com PC } & \text { Paraíba } & \begin{array}{l}\text { Março a } \\ \text { abril de }\end{array} & \begin{array}{l}\text { Pesquisa qualita- } \\ \text { tiva, explorató- }\end{array} & \begin{array}{l}\text { Apreender as facilida- } \\ \text { des e as dificuldades da } \\ \text { família no cuidado às } \\ \text { crianças com PC }\end{array}\end{array}$

$\begin{array}{lllll}\begin{array}{l}\text { A fragilidade clínica e } \\ \text { a vulnerabilidade social } \\ \text { das Crianes }\end{array} & \begin{array}{l}\text { Rio Grande } \\ \text { do Sul }\end{array} & \begin{array}{l}\text { Entre 2004 } \\ \text { e 2005 }\end{array} & \begin{array}{l}\text { Estudo } \\ \text { qualitativo }\end{array} & \begin{array}{l}\text { Analisar e discutir a } \\ \text { dimensáo do cuidado } \\ \text { físico às Crianes }\end{array}\end{array}$

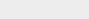

Quadro 1: Continuação.

$\begin{array}{lllll} & \begin{array}{l}\text { Local da } \\ \text { pesquisa }\end{array} & \begin{array}{l}\text { Período da } \\ \text { pesquisa }\end{array} & \begin{array}{l}\text { Método de } \\ \text { pesquisa }\end{array} & \text { Objetivo principal } \\ \begin{array}{l}\text { Análise do cuidado a } \\ \text { partir das experiências } \\ \text { das mães de crianças } \\ \text { com PC }\end{array} & \begin{array}{l}\text { Fortaleza, } \\ \text { Ceará }\end{array} & \begin{array}{l}\text { Fevereiro a } \\ \text { agosto de }\end{array} & \begin{array}{l}\text { Hermenêutica } \\ \text { heideggeriana }\end{array} & \begin{array}{l}\text { Analisar o cuidado a } \\ \text { partir da experiência } \\ \text { das mães cuidadoras de } \\ \text { crianças com PC }\end{array}\end{array}$

\section{Principais resultados}

Urgência de efetivar um cuidado centrado na alteridade, possibilitando novas incursões e revisitaçôes da qualidade do cuidado prestado pelos profissionais de saúde.

Com o tempo, as dificuldades cedem lugar à rotina e à adaptaçáo à vida diária da criança. Estreitar relaçôes com a família, melhorando o vínculo e desenvolvendo açóes de qualidade e integrais, promove o bem-estar da criança com PC e de sua família.

Os achados indicaram que elas são clinicamente frágeis e socialmente vulneráveis. Consequentemente, suas cuidadoras familiares enfrentam, no cuidado domiciliar, desafios relacionados à complexidade do cuidar e à condição feminina

As mulheres revelaram a natureza complexa do cuidado às Crianes e a

Descrever e discutir os desafios determinados por esses cuidados para as cuidadoras de Crianes no domicílio.
Cuidar de Crianes: desafios para as famílias e enfermagem pediátrica
Rio Grande do Sul
Dezembro
de 2004

Pesquisa qualitativa relevância de realizá-lo com base em saberes e práticas que não pertencem ao seu cotidiano existencial. Elas situam esse cuidado como de sobrevivência, (sobre)natural e singular devido à sua complexidade e elevada demanda de dedicação.

A interação familiar com a criança melhorou após a obtenção de maiores esclarecimentos sobre a sua saúde. As cuidadoras assumem papel proativo no processo reabilitador do filho. Elas aprenderam a relevar o estigma imputado aos seus filhos, mas enfrentam agravos à sua saúde, dificuldades financeiras e barreiras para conduzir seus filhos até o serviço de reabilitação devido à insipiente oferta de transporte intermunicipal.

Os resultados apontaram que a Crianes possui uma rede social institucional e uma rede social familiar.

O cuidado familiar à Santa Maria, Crianes no contexto da Rio Grande comunidade do Sul
Descrever a rede social de uma Crianes no contexto da comunidade
Os serviços de atenção primária foram considerados pelos sujeitos como de difícil acesso e, por esse motivo, não eram utilizados pela criança 


\section{A importância dos profissionais de enferma- gem e da assistência em saúde quanto aos cuidados às Crianes}

Em estudo realizado com o intuito de conhecer os exercícios do profissional de saúde com diversas faces do cuidar, abordando uma reflexão sobre o cuidado, elencou-se a necessidade de um amadurecimento teórico que compóe o cuidado em saúde, como as concepçóes abrangentes necessárias para lidar com a criança especial em sua complexidade e subjetividade. Tal postura possibilita maior aproximaçáo do profissional de saúde com a realidade da criança, e isso oferece maior significado do que é um cuidado humanizado e integral ${ }^{9}$.

A assistência a essas crianças, por vezes, fica reduzida somente à realização das técnicas de cuidado em saúde, o que gera questionamentos sobre a amplitude do conceito de saúde, uma vez que tais crianças podem demandar muitos outros cuidados além daqueles relacionados apenas ao corpo biológico ${ }^{10}$. A criança portadora de necessidades especiais precisa de estratégias para melhorar a qualidade de vida e o processo saúde-doença, pois este se encontra interligado com a busca pelo bem-estar, com superação do olhar exclusivamente biológico da avaliação em saúde ${ }^{11}$. Pensando nisso, o cuidado a essas crianças não se limita somente a um conjunto de técnicas a serem desenvolvidas, mas envolve outras estratégias de cuidado, como o toque, determinando aproximação e criação de vínculo ${ }^{10}$.

As estratégias citadas contribuem para a autonomia, o amadurecimento e o desenvolvimento das Crianes. O foco da atenção não pode ser direcionado apenas as suas limitaçóes, sendo que estas precisam ser percebidas em uma perspectiva integral de saúde. Sendo assim, é importante considerar que cada criança precisa de atenção, dedicaçáo, carinho e respeito para o planejamento de um cuidado baseado em suas necessidades especiais ${ }^{11}$.

Como visto, os profissionais de enfermagem não devem se pautar nas diferenças e limitaçóes da criança especial, mas reconhecer o potencial que possibilita a melhora na qualidade de vida, tornando-se extremamente importante no desenvolvimento dessas crianças, possibilitando a autonomia e favorecendo o fluxo de cuidados específicos, sejam eles básicos ou complexos ${ }^{10}$.

Esses cuidados só se tornam efetivos quando há interação entre o profissional e a criança, permitindo o estabelecimento de melhores condiçóes para ela. A assistência é importante para reabilitação/habilitação da criança, e assim, a enfermagem possui um papel significativo nesse cenário, pois quando há uma comunicação bem-sucedida entre os profissionais e as crianças, todo cuidado prestado resulta numa assistência de qualidade ${ }^{12}$.
Destaca-se, ainda, a grande importância dos profissionais em lutar por um sistema de saúde que favoreça a inclusão da Criane e de sua família ${ }^{13}$. Esta busca uma instituição com a esperança de ser acolhida e de receber o que precisa, porém permanece desprovida de acompanhamento e assistência adequados e direcionados às demandas de cuidados de seus filhos. Dependendo da condiçâao de saúde da criança, a família tem de arcar financeiramente com a maioria das demandas, pois o sistema não atende a todas as açóes requeridas. As políticas públicas desempenham um papel importante e, assim, deveriam garantir acesso ao acompanhamento dessas crianças, mas nem todos os recursos necessários para reabilitação, inclusão e sustentação das famílias são disponibilizados ${ }^{14}$.

Além da falta de disponibilidade de todas as ações requeridas pela criança por parte das políticas públicas de saúde, enfatizam-se as dificuldades para a acessibilidade aos serviços de saúde, como a falta de estrutura como uma ocorrência comum nos estabelecimentos de saúde em todo o país. Evidenciam-se açóes que possam repercutir na melhoria da acessibilidade aos serviços de saúde, por meio da priorizaçáo do atendimento e da visita domiciliar, avaliando o contexto do usuário e suas demandas para estabelecer um plano assistencial para cada criança e família ${ }^{15}$.

Apesar de os profissionais de enfermagem pretenderem assegurar o atendimento a todos os cidadãos, ainda existem empecilhos para que as Crianes recebam a assistência preconizada pelo Sistema Único de Saúde (SUS). Diante disso, com as dificuldades de acesso incluem-se também a relação paciente-profissional, uma vez que as deficiências sensitivas estabelecem barreiras no sentido de interação ${ }^{16}$.

As famílias dessas Crianes precisam de profissionais preparados para orientá-las, que levem em consideração seus sentimentos e particularidades ${ }^{9}$. Diante disso, os profissionais devem estar preparados para oferecer determinadas informaçóes para direcionar os familiares quanto aos cuidados necessários à criança, demandando dos profissionais uma base teórica que contribua na orientação e no apoio às famílias ${ }^{17}$. Portanto, destaca-se como estratégia de intervenção importante a educação em saúde, tendo como alvo da açáo educativa o conhecimento dos familiares cuidadores e suas demandas de aprendizagem para cuidar de uma Crianes ${ }^{18}$.

Sendo assim, identifica-se que o acesso das Crianes aos serviços de atenção ocorre com dificuldade, mas considera-se que os usuários dessas instituições podem intervir/contribuir e serem ouvidos pelos profissionais, podendo assim planejar açóes condizentes com a realidade e expectativa para melhorar a acessibilidade a tais serviços ${ }^{15}$. Sugere-se a inclusão de programas educativos 
na rotina de instituiçóes reabilitadoras, como ambiente para que os profissionais possam melhor orientar os familiares acerca do estado de saúde da criança e dos cuidados necessários, dando destaque para a criação de políticas públicas que assegurem uma rede social de apoio que auxilie os cuidadores a melhor cuidar de si próprio e da criança $a^{19}$.

Apesar de a existência de muitos trabalhos científicos acerca da inclusão de indivíduos com alguma deficiência, percebe-se uma restrição em abordar o tema sob o ponto de vista do impacto na família ${ }^{19}$. Além disso, em estudo realizado com intuito de descrever a rede social de uma criança com necessidades especiais de saúde no contexto da comunidade, ressaltou-se a invisibilidade do enfermeiro no discurso dos pais cuidadores, uma vez que, em nenhum momento, a enfermagem foi citada, inclusive quando questionados sobre as orientaçóes dadas durante a internação e a alta hospitalar, evidenciando a fragilidade de vínculo da enfermagem com a família ${ }^{20}$.

Os profissionais de enfermagem devem reconhecer a dimensão do processo de cuidado a uma Criane, pois desenvolvem um papel importante como protagonistas no atendimento da demanda de cuidados. Sendo assim, há uma grande necessidade de desenvolver estratégias para o cuidado integral e humanizado a essas crianças, bem como de envolver a família. Para isso, a enfermagem precisa estar preparada e capacitada para desenvolver sua assistência de forma clara e objetiva, estabelecendo vínculo e melhorando o atendimento e a prestação de cuidados.

\section{Impacto familiar frente aos cuidados à criança com necessidades especiais de saúde}

O impacto na família em relação aos cuidados que as Crianes exigem está diretamente ligado às inúmeras medidas de readaptação às atividades cotidianas, cujas práticas náo pertenciam ao contexto de vida dessas famílias $^{21}$. Essas crianças geralmente possuem doenças complexas que necessitam de cuidados mais especializados $^{18}$. Algumas crianças podem requerer hospitalização, gerando um aumento na demanda da assistência, e nessas instituiçôes quem realiza grande parte dos cuidados são os membros da equipe de enfermagem. Porém, quando essas crianças recebem alta, quem realiza todo o cuidado é a família ${ }^{21}$.

Os pais evidenciam que, na descoberta do diagnóstico de necessidades especiais, há um grande sentimento de frustração do sonho de um filho saudável que não possui nenhuma demanda em saúde. Além disso, os familiares relatam outros problemas durante a transmissão do diagnóstico, ora pela excessiva utilização de termos técnicos por partes dos profissionais de saúde, ora por não acreditarem nas informaçóes transmitidas sobre o diagnóstico de seu filho, desejando buscar outras fontes de conhecimento ${ }^{22}$. Por isso, há uma grande necessidade de transmitir as informaçóes sobre o diagnóstico da criança de forma clara e humanizada, de forma a facilitar o entendimento por parte da família e contribuir para evitar algum tipo de risco que possa gerar conflitos.

Essas dificuldades mencionadas demandam muito apoio e acolhimento dos profissionais de saúde, os quais devem aproveitar o encontro com a família para ajudarem a esclarecer dúvidas e estarem sempre dispostos a escutar o que a família tem a dizer ${ }^{23}$. Sendo assim, o cuidado com as famílias que têm a experiência de ter um filho com necessidades especiais é importante para o fortalecimento delas no enfrentamento das dificuldades.

Evidencia-se a importância da família em adquirir conhecimentos técnicos e científicos para atender à demanda de cuidados que essas crianças requerem. Desse modo, ressalta-se a importância da enfermagem em instrumentalizar e preparar a família para cuidar adequadamente de uma Crianes ${ }^{24}$. O profissional deve partilhar informaçóes sobre a saúde e os cuidados direcionados à criança de forma franca, dando oportunidade aos familiares de participarem dos cuidados e das tomadas de decisóes ${ }^{13,18}$, pois eles têm o direito de explicaçóes claras e apropriadas que auxiliam na busca pelo bem-estar dessas crianças.

Cabe ressaltar também que as rotinas familiares são muito afetadas perante situações de mudança e estresse, salientando-se, assim, a falta de preparo das famílias para dar continuidade ao tratamento e aos cuidados em casa. Desse modo, há uma rotina de cuidados que as famílias precisam adaptar ao seu cotidiano e trazem consequências até no comprometimento do orçamento familiar ${ }^{25}$. Considerando as rotinas de cuidados, por mais que estes demandem tempo e até dificuldades por parte das famílias, é importante estabelecer uma rotina, porque tal medida pode ajudar na promoção de saúde e na organização do cotidiano e, dessa forma, as famílias conseguem realizar todas as tarefas necessárias. Por diversas vezes, as rotinas são cansativas, porém elas fornecem auxílio na adaptação às necessidades relacionadas ao estado de saúde ${ }^{26}$.

De acordo com a gravidade da criança, os cuidados podem permanecer ao longo de toda a vida e pode ser que, com o passar dos anos, estes se tornem cada vez mais difíceis, sendo excessivos e até intermináveis. À medida que a criança cresce é que se percebe o agravamento da situaçấo de saúde, pois as necessidades especiais ficam mais evidentes ${ }^{25}$. A situaçáo especial da criança pode trazer a sensação de competência e 
confiança dos pais, gerando assim a busca por adaptação a uma nova realidade, tentando reorganizar-se para enfrentar a experiência de viver e conviver com a criança. Essa situação traz sentimentos de vulnerabilidades e reajustes emocionais que demandam tempo. Nessas experiências, há famílias que conseguem passar pelo desafio, enquanto outras têm um pouco mais de dificuldade, limitando a possibilidade de se organizarem e causando riscos na sua estrutura ${ }^{13}$.

Como já mencionado, pais e famílias de Crianes acabam enfrentando também algumas dificuldades financeiras em relação aos cuidados especializados, pois estes são de alto custo. Relata-se que a baixa renda associada aos custos com tratamentos especializados e medicamentos, por vezes muito caros, causam angústia e desconforto a essas famílias. O impacto financeiro costuma ser maior em famílias em que pelo menos um membro teve de parar de trabalhar para cuidar da criança após alta hospitalar ${ }^{27}$.

O impacto da necessidade especial da criança é evidente nas famílias que sofrem algum tipo de modificação na rotina, no lazer e no convívio entre seus membros e existe até a possibilidade de mudança geográfica, porque elas podem ter de mudar de cidade em busca de um tratamento melhor para os filhos ${ }^{28}$. Muitas vezes, percebe-se a ausência de referência e contrarreferência após a alta hospitalar, o que dificulta a trajetória dos familiares/cuidadores, levando-os a criar uma rede própria em busca de atendimento ${ }^{20}$. Para cuidar de seu filho, a família busca apoio em três grupos sociais: grupos familiares, que inclui amigos e vizinhos; grupo composto por profissionais de saúde envolvidos no cuidado a criança; por último, o grupo religioso ${ }^{24}$.

Além disso, foi evidenciado como elemento positivo frequentar instituiçôes de reabilitação, assim como o ambiente escolar, algo destacado na literatura como um aspecto importantíssimo, pois melhora o desenvolvimento motor, sensorial, cognitivo e, principalmente, social da criança, levando-se em conta o estímulo recebido por meio da interação social ${ }^{26}$. A família deve ter sua importância reconhecida, principalmente pelos profissionais de saúde, para então poder participar efetivamente no processo de cuidados com segurança e recebendo todas as condiçóes necessárias para auxiliar no desenvolvimento, crescimento e qualidade de vida das crianças.

\section{Conclusão}

Na busca por estudos que abordassem a criança e a assistência em saúde, constatou-se que as tendências destes estáo voltadas mais para o papel da família, porém ainda existe um grande despreparo dessa em dar continuidade ao tratamento da criança em casa. Isso ocorre por conta de um distanciamento entre a equipe de saúde e família, pois os familiares não têm sido atendidos como um todo diante da situação do filho com necessidades especiais de saú$\mathrm{de}$, muito porque a equipe centra seus cuidados somente na atençáo biomédica. $\mathrm{O}$ foco continua sendo a patologia e a família fica em segundo plano, sem informaçōes claras a respeito do diagnóstico do filho, e por diversas vezes, sem participar da tomada de decisóes e dos cuidados.

Diante disso, ressalta-se que é extremamente necessário e fundamental que a enfermagem desenvolva habilidades para cuidar também da família, compreendendo suas limitaçóes, esclarecendo dúvidas e dando a esta oportunidade de participação em todas as etapas do processo do cuidado. Assim, há uma grande necessidade de priorizar o vínculo entre profissional-criança-família, pois isso ajuda na reabilitação, melhora o atendimento, a prestação de cuidados e a qualidade da assistência.

Sabe-se ainda que há um outro tipo de despreparo por parte dos profissionais, ligado ao conhecimento científico na área, pois a criança possui uma série de cuidados especiais, tornando-se necessário que a enfermagem esteja mais preparada e capacitada para atuar nas demandas de cuidados durante a internaçáo e orientar a família na continuidade ao tratamento no meio domiciliar. Por fim, ressalta-se que é preciso incentivar e investir em novas pesquisas nessa área, pois ainda há poucos resultados acerca do tema na literatura. Assim, poderemos conhecer melhor as estratégias que podem ser utilizadas nos cuidados dessas crianças, possibilitando mais discussão sobre a assistência que, consequentemente, ajudará a melhorar o cuidado.

\section{Referências}

1. Whaley LF, Wong DL. Enfermagem pediátrica: elementos essenciais à intervenção efetiva. 5a ed. Rio de Janeiro: Guanabara Koogan; 1999.

2. McPherson M, Arango P, Fox H, Lauver C, McManus M, Newacheck PW, et al. A new definition of children with special health care needs. Pediatrics. 1998;1(102):137-41.

3. Neves ET, Cabral IE. A fragilidade clínica e a vulnerabilidade social das crianças com necessidades especiais de saúde. Rev Gaúcha Enferm. 2008;29(2):183.

4. Neves ET. A prática de enfermagem pediátrica em tempos de crianças com necessidades especiais de saúde. Rev Soc Bras Enferm Ped. 2008;8(2):55-6.

5. Organização das Naçóes Unidas. A ONU e as pessoas com deficiência [Internet]. Brasília, DF: Organização das Naçôes Unidas; 2017 [citado em 2017 out 30]. Disponível em: https://goo.gl/xRUazG 
6. Ferraz L, Almeida FM, Girardi F, Soares SC. Assistência de enfermagem na promoção do autocuidado aos portadores de necessidades especiais. Rev Enferm UERJ. 2007;15(4):597-600.

7. Silveira A, Neves ET. Crianças com necessidades especiais de saúde: tendências das pesquisas de enfermagem. Rev Enferm UFSM. 2011;1(2):254-60.

8. Mendes KDS, Silveira RCCP, Galvão CM. Revisão integrativa: método de pesquisa para a incorporação de evidências na saúde e na enfermagem. Texto Contexto Enferm. 2008;17(4):758-64.

9. Pereira, ARPF, Matsue RY, Vieira LJES, Pereira RVS. Análise do cuidado a partir das experiências das mães de crianças com paralisia cerebral. Rev Saúde Soc. 2014;23(2):612-25.

10. Soares MZV, Bitencourt JVOV, Parker AG, Borges AMF, Vargas MAO, Schoeller SD. A influência do toque no cuidado às crianças especiais. Rev Enferm UFSM. 2014;4(1):76-86.

11. Milbrath VM, Siqueira HCH, Amestoy SC, Cestari ME. Criança portadora de necessidades especiais: contrapontos entre a legislação e a realidade. Rev Gaúcha Enferm. 2009;30(1):127-30.

12. Vargas JS, Rezende MS. Comunicação: equipe de enfermagem e paciente em ventilação mecânica. Rev Enferm UFSM. 2011;1(3):412-33.

13. Barbosa MAM, Balieiro MMFG, Pettengill MAM. Cuidado centrado na família no contexto da criança com deficiência e sua família: uma análise reflexiva. Texto Contexto Enferm. 2012;21(1):194-9.

14. Holanda ER, Collet N, Costa SFG. Crianças com Síndrome de Down: o significado do cuidar na percepção de mães. Online Braz J Nurs [Internet]. 2008 [citado $2017 \mathrm{fev}$ 7];7(2). Disponivel em: https://goo.gl/i4HCu4.

15. Rosário SSD, Fernandes APNL, Batista FWB, Monteiro AI. Acessibilidade de crianças com deficiência aos serviços de saúde na atenção primária. Rev Eletr Enferm [Internet]. 2013 [citado em 2017 fev 8];15(3):740-6. Disponível em: https://goo.gl/u7gyNT.

16. França ISX, Pagliuca LMF. Acessibilidade das pessoas com deficiência ao SUS: fragmentos históricos e desafios atuais. Rev RENE. 2008;9(2):129-37.
17. Gondim KM, Carvalho ZMF. Sentimentos das mães de crianças com paralisia cerebral à luz da Teoria de Mishel. Esc Anna Nery. 2012;16(1):11-6.

18. Neves ET, Cabral IE. Cuidar de crianças com necessidades especiais de saúde: desafios para as famílias e enfermagem pediátrica. Rev Eletr Enferm [Internet]. 2009 [citado em 2017 fev 8];11(3). Disponível em: https://goo.gl/aUJzzk.

19. Silva CX, Brito ED, Sousa FS, França ISX. Criança com paralisia cerebral: qual o impacto na vida do cuidador. Rev RENE. 2010;11(Supl):204-14.

20. Zamberlan KC, Neves ET, Silveira A, Paula CC. O cuidado familiar à criança com necessidades especiais de saúde no contexto da comunidade. Cienc Cuid Saude. 2013;12(2):290-7.

21. Simonasse MF, Moraes JRMM. Crianças com necessidades especiais de saúde: impacto no cotidiano familiar. Rev Pesqui Cuid Fundam Online [Internet]. 2015 [citado em 2017 fev 8];7(3):2902-9. Disponível em: https://goo.gl/ zv6D7n.

22. Milbrath VM, Soares DC, Amestoy SC, Cecagno D, Siqueira $\mathrm{HCH}$. Mães vivenciando o diagnóstico da paralisia cerebral em seus filhos. Rev Gaúcha Enferm. 2009;30(3):437-44.

23. Toly VB, Musil CM, Carl JC. Families with children who are technology dependent: normalization and family functioning. West J Nurs Res. 2012;34(1):52-71.

24. Moraes JRMM, Cabral IE. The social network of children with special healthcare needs in the (in)visibility of nursing care. Rev Latino-Am Enfermagem. 2012;20(2):282-8.

25. Rocha PFA, Boehs AE, Silva AMF. Rotina de cuidados das famílias de crianças com paralisia cerebral. Rev Enferm UFSM. 2015;5(4):650-60.

26. Dantas MSA, Pontes JF, Assis WD, Collet N. Facilidades e dificuldades da família no cuidado à criança com paralisia cerebral. Rev Gaúcha Enferm. 2012;33(3):73-80.

27. Kuhlthau K, Kahn R, Hill KS, Gnanasekaran S, Ettner SL. The well-being of parental caregivers of children with activity limitations. Matern Child Health J. 2010;14(2):155-63.

28. Cagran B, Schmidt M, Brown I. Assessment of the quality of life in families with children who have intellectual and developmental disabilities in Slovenia. J Intellect Disabil Res. 2011;55(12):1164-75.

\section{Como citar este artigo:}

Inácio ALR, Peixoto APGL. A assistência de enfermagem e o cuidado familiar às crianças com necessidades especiais de saúde: uma revisão integrativa. Rev. Aten. Saúde. 2017;15(53):87-94. 